\title{
Tiroid Fonksiyon testlerinin analitik performansının değerlendirilmesinde; 6 sigma metodolojisi
}

\section{Evaluation of Analytical Performance of Thyroid Function Tests: 6 Sigma Methodology \\ Müigan ERCAN KARADAĞ 1 이, Adnan KiRMiт 1}

1 Harran Üniversitesi Tıp Fakültesi, Tıbbi Biyokimya ABD, Şanlıurfa, Türkiye

Öz.

Amaç: Altı sigma seviyesi, performansın değerlendirilmesi ve karşılaştırılmasında kalitenin bir ölçütüdür. Altı Sigma ölçümü, internal kalite kontrol (IKK) stratejisi oluşturmak ve sıklığını planlamak için klinik laboratuvar rehberliğinde bir öz değerlendirme yöntemi olarak kullanılabilir. Çalışmamızda rutinde en çok istenen testlerden olan tiroid fonksiyon panelinin (TSH, sT3 ve sT4) analitik aşamasının sigmametrik değerlendirmesini amaçladık.

Materyal ve Metod: Retrospektif olarak incelediğimiz 3 aylık TSH, sT3 ve sT4 testlerinin sigma değerlerini; bias, varyasyon katsayısı ve toplam izin verilebilir hata (TEa) parametrelerini kullanarak belirledik. Bias'ı, İKK hedef verilerinden; varyasyon katsayısını ise İKK verilerinden yararlanarak hesapladık. TEa parametresini; Ricos'un biyolojik varyasyon verilerine göre belirledik. Sigma ölçütlerine göre analitik performans değerlendirmesinde ">5", "4-5", "3-4" ve "<3" değerlerini sırasıyla "çok iyi", "iyi", "minimum" ve "kabul edilemez" olarak kategorize ettik.

Bulgular: TSH, sT3 ve sT4 testlerinin her üç İKK seviyesinin 3 aylık verilerine göre hesapladığımız sigma değerlerini sırasıyla $>3.74,>2.27$ ve $>1.73$ olarak bulduk.

Sonuç: Tiroid fonksiyon testlerinin analitik performansını 6 sigmaya göre değerlendirdiğimizde; TSH performansının iyi, sT3 ve sT4 performansının ise düzeltilmesi gereken durumda olduğunu saptadık. Genellikle laboratuvarlar İKK verilerinden elde edilen varyasyon katsayısı ile analitik dönem kalitesini yönetse de, sigmametrik değerlendirme daha sıkı bir İKK yapmamız gerektiğini bize göstermiştir.

Anahtar kelimeler: 6 sigma, TSH, sT3, sT4, İç kalite kontrol

\section{Abstract}

Background: Sigma metric evaluation is a measure of quality in evaluating and comparing analytical performance in laboratories. Six Sigma can be used as a clinical analytical phase assessment methodology to form an internal quality control (IQC) strategy and plan its frequency. In this study, we aimed to evaluate the analytical performance of thyroid function panel (TSH, sT3 and ST4) which is one of the most requested tests in routine.

Materials and Methods: We analyzed six sigma levels via using IQC results retrieved from laboratory information system for three months period. Both bias and variation coefficient were calculated from the internal quality control results. TEa parameter; based on the biological variation data of Ricos. The calculated sigma values were classified as follows: ">5", "4-5", "3-4" and "<3" very good, good, minimum and unacceptable respectively.

Results: The sigma values of TSH, fT3 and fT4 tests according to the 3-month data of all three IQC levels were found to be $>3.74,>2.27$ and $>1.73$, respectively.

Conclusion: Our result showed that TSH performance is good and sT3 and sT4 performance are unacceptable. Generally, although the laboratories manage the analytical period quality with the coefficient of variation obtained from IQC data, sigma metric evaluation has shown us that we should make a stricter IQC.

Key words: 6 sigma, TSH, fT3, fT4, Internal quality control

\section{Sorumlu Yazar I \\ Corresponding Author}

Müjgan ERCAN KARADAĞ

Harran Üniversitesi Tıp Fakültesi

Araştırma ve Uygulama Hastanesi

Tıbbi Biyokimya ABD,

Osmanbey Kampüsü 63300

Haliliye Şanlıurfa

Geliş tarihi / Received:

30.07.2019

Kabul tarihi / Accepted:

09.12.2019

DOI: $10.35440 /$ hutfd. 598537 


\section{Giriş}

Tıbbi laboratuvarların hastalık tanı ve tedavisindeki yeri $\% 70$ den daha fazla etkin konuma gelmiştir (1). Bu amaç doğrultusunda; tıbbi laboratuvarlar doğru, kesin ve karşıIaştırılabilir sonuçlar üretmek zorundadırlar. Tıbbi laboratuvarlarda preanalitik, analitik ve postanalitik olarak adlandırılan üç evre gerçekleşmektedir ve literatürlerde verilen hata oranları sırası ile $\% 62, \% 23$ ve $\% 15$ dir (2). Her bir evrede gerçekleşen hataların etkisinin değerlendirilmesi, hastanın sağlık hizmetlerinden olumsuz etkilenmemesi açısından önem taşımaktadır. Bu süreçlerin her birinin sürekli olarak denetlenebilir ve geliştirilebilir olması gerekmektedir (2). Analitik evre standardizasyonu, otomasyon ve teknolojik gelişmeler, iç kalite kontrol (IKK) ve dış kalite kontrol değerlendirmeleri laboratuvar sonuçlarının güvenilirliğini önemli ölçüde gelişmiş̧ir (3).

Analitik süreçlerin değerlendirilmesine yönelik önemli bir yaklaşım, altı sigma konseptinin kullanımasıdır (4). İlk olarak Endüstri alanındaki hataların değerlendirilmesinde kullanılan bu yöntem laboratuvar hatalarını değerlendirmede sıklıkla kullanılmaya başlanmıştır. Altı sigma; hataları değerlendirmek ya da hata oranlarını saptamak için uygulanabilecek bir kurallar dizisidir (5). Sigma ölçüm modeli, bir yöntemin performansını değerlendirmek için objektif bir değerlendirme sağlar. Bu ölçüt, süreç performansını milyon fırsat başına kusur oranı olarak belirlemektedir $(4,6)$. Klinik laboratuvar testlerinin ölçümlerindeki temel analitik kriterler yanlılık (bias) ve tekrarlanabilirlikdir ( CV). Hedeflenen dağılım aralığı; toplam izin verilen hatadır (TEa) ve buna göre analitik sürecin sigma düzeyi $=[($ TEa - Bias $) / C V]$ formülü kullanılarak hesaplanabilir (2).

Altı sigma değerlendirmesi, İKK (İnternal Kalite Kontrol) stratejisi oluşturmak ve IKK sıklığını planlamak için klinik laboratuvar rehberliğinde bir öz değerlendirme yöntemi olarak kullanılabilir. Doğru ve güvenilir ölçüm sonuçları elde etmek için, klinik laboratuvar günlük analitik süreçlerine bu ölçütleri uygulamak yararlıdır.

Tiroid fonksiyon testlerinde analitik evre, subklinik hipotiroinin klinik belirti olmadan sadece laboratuvar testleri ile ortaya çıkarılabilmesi açısından çok önemlidir. Bu noktadan hareketle çalışmamızda, tiroid fonksiyon testlerinin analitik aşamasını sigmametrik değerlendirerek; analitik performansı ve ayrıca kalite kontrol stratejisini ortaya koymayı amaçladık.

\section{Materyal ve Metod}

Çalışmamızda Harran Üniversitesi Araştırma ve Uygulama Hastanesi Biyokimya Laboratuvarı Ocak-Mart 2019 aylarına ait sT3, sT4 ve TSH testlerinin IKK verileri Laboratuvar Bilgi Sisteminden alınmıştır.

Tiroid fonksiyon testleri ADVIA Centaur CP Immunoassay system (Irlanda) cihazında çalışılmıştır. Üç aylık süre içinde günlük olarak analiz edilen aynı lot numaralı 3 seviyeli IKK numuneleri (level 1:40361, level 2: 40362, level 3:
40333) kullanılmıştır. Bu çalışmada, Bio-Rad firmasının prospektüsünde önerdiği IKK hedef değerleri referans olarak kullanıldı. Ocak-Mart 2019 tarihleri arasında her ay için ayrı ayrı olmak üzere her bir testin \% Bias değeri hesaplandı. TEa, biyolojik varyasyon ve analitik yöntemin performansına göre belirlenmektedir. Bu çalışmada westgard biyolojik varyasyon veritabanında yer alan TEa oranları kullanılarak sigmametrik performans değerleri hesaplandı (7). Varyasyon katsayısı (CV), Bias ve sigma değerleri aşağıdaki formülasyonlara göre hesaplandl:

Varyasyon katsayısı (CV\%):

Bir veri setinden elde edilen standart sapmanın (SD) ortalamaya $(\bar{x})$ oranının yüzde olarak ifade edilmesidir ve şu şekilde hesaplanmıştır:

CV $(\%)=($ SD / IKK verilerinin ortalaması $) \times 100$

Bias:

Her bir testin her ay (Ocak-Mart 2019) için ayrı ayrı \% Bias değerleri şu formülle belirlendi:

$\%$ Bias $=[($ laboratuvarımızın IKK ortalaması - İKK hedef değeri) / IKK hedef değeri] $\times 100$

Sigma değeri: İKK verilerinden elde edilen varyasyon katsayıSI (CV), IKKK verilerinin hedef değerlerinden elde edilen bias ve toplam izin verilebilir hata (TEa) kullanılarak, şu şekilde hesaplanmıştır:

Sigma $=(\% \mathrm{TEa}-\%$ Bias $) \div \% \mathrm{CV}$

Her testin analitik performans özelliklerini belirlemek için sigma değerleri hesaplandı. Sigma değeri ">5", "4-5", "34 " ve "<3" değerleri sırasıyla "çok iyi", "iyi", "minimum" ve "kabul edilemez" olarak kategorize edildi (8).

\section{Bulgular}

Her bir tirod fonksiyon testinin üç seviyesi için, firmanın verdiği prospektüste belirtilen İKK hedef değerleri, laboratuvarın ortalaması ve SD değerleri Ocak-Mart 2019 ayları için Tablo 1'de özetlenmiştir. Standart sapma sonuçları laboratuvarımızda kural ihlali olarak kabul ettiğimiz $\pm 2 S D$ hedefleri içinde değerlendirilmiştir. Tablo-2'de TSH, sT3 ve sT4'ün level 1, 2 ve 3 için hesaplanan \% Bias, CV(\%) ve sigma değerleri yer almaktadır.

\section{Tartışma}

Tiroid testlerinin analitik evrede takibi, subklinik hipotiroidinin tanısı açısından büyük önem taşımaktadır. Subklinik hipotiroidi; sT3 ve sT4 genellikle normal düzeylerde seyrederken, TSH düzeyi ise genellikle yüksek olan bir laboratuvar tanısıdır. Bu tanıda, tiroid fonksiyon bozukluğuna ait klinik belirti ve bulgular olmayabilir ya da çok az görülür. Hashimoto tiroiditi ve tiroid karsinomu gibi ciddi klinik tabloların ilk bulgusu olarak karşımıza çıkabilen subklinik hipotiroidinin tanısı önem arz etmektedir (9).

Çalışmamızda laboratuvarımızda çalıştığımız tiroid fonksiyon testleri performansını sigmametrik olarak değerlendirdik. Bulgularımız TSH'nın sT3 ve sT4'e göre daha iyi sigma değerlerine sahip olduğunu göstermiştir. Bununla birlikte, 
bu testler kendi içide aylara göre değerledirildiğinde ise arada büyük bir farklılığın olmadığını tespit ettik. Literatürde immunokimya testlerinin sigma ölçütü kullanılarak değerlendirildiği çok az makale bulunmaktadır.

Tablo 1 Her testin hedef değeri, laboratuvar ortalaması ve SD değerleri

\begin{tabular}{lllllllllll}
\hline & \multicolumn{1}{c}{ TSH } & \multicolumn{3}{c}{ sT3 } & \multicolumn{5}{c}{ sT4 } \\
\hline \multirow{6}{*}{} & $\begin{array}{l}\text { Level } \\
\text { (Seviye) }\end{array}$ & 1 & 2 & 3 & 1 & 2 & 3 & 1 & 2 & 3 \\
\cline { 2 - 11 } & $\begin{array}{l}\text { Hedef } \\
\text { değer }\end{array}$ & 0.45 & 6.15 & 37 & 2.41 & 6.80 & 11.75 & 0.86 & 2.12 & 4.44 \\
\hline \multirow{2}{*}{ Ocak } & Ortalama & 0.50 & 6.12 & 36.99 & 2.49 & 6.94 & 11.73 & 0.83 & 2.13 & 4.41 \\
& SD & 0.02 & 0.27 & 1.64 & 0.04 & 0.12 & 0.43 & 0.01 & 0.05 & 0.10 \\
\hline \multirow{2}{*}{ Subat } & Ortalama & 0.47 & 6.66 & 39.59 & 2.52 & 7.01 & 12.21 & 0.84 & 2.13 & 4.41 \\
& SD & 0.01 & 0.23 & 1.53 & 0.05 & 0.12 & 0.29 & 0.01 & 0.05 & 0.10 \\
\hline \multirow{2}{*}{ Mart } & Ortalama & 0.44 & 6.46 & 37.15 & 2.41 & 6.78 & 12 & 0.87 & 2.13 & 4.41 \\
& SD & 0.02 & 0.23 & 1.59 & 0.15 & 0.25 & 0.39 & 0.02 & 0.05 & 0.10 \\
\hline
\end{tabular}

Tablo 2. Tiroid fonksiyon testleri için üç kalite kontrol seviyesinin, TEa, Bias(\%), CV(\%) ve sigma değerleri.

\begin{tabular}{|c|c|c|c|c|}
\hline & & TSH & sT4 & sT3 \\
\hline \multirow{4}{*}{ Ocak Level 1} & TEa(\%) & 23.7 & 8 & 11.3 \\
\hline & CV(\%) & 4.57 & 1.37 & 1.47 \\
\hline & $\operatorname{Bias}(\%)$ & 0.35 & 3.88 & 3.23 \\
\hline & Sigma & 5.11 & 2.99 & 5.48 \\
\hline \multirow{3}{*}{ Ocak level 2} & CV(\%) & 4.45 & 2.19 & 1.74 \\
\hline & Bias(\%) & 0.54 & 0.28 & 2.04 \\
\hline & Sigma & 5.20 & 3.51 & 5.33 \\
\hline \multirow{3}{*}{ Ocak level 3} & CV(\%) & 4.46 & 2.31 & 3.74 \\
\hline & $\operatorname{Bias}(\%)$ & 0.02 & 0.73 & 3.14 \\
\hline & Sigma & 3.74 & 3.14 & 2.93 \\
\hline \multirow{3}{*}{ Şubat Level 1} & CV(\%) & 3.02 & 1.38 & 2.08 \\
\hline & Bias(\%) & 4.14 & 2.47 & 4.74 \\
\hline & Sigma & 6.46 & 3.98 & 3.15 \\
\hline \multirow{3}{*}{ Şubat level 2} & CV(\%) & 3.44 & 2.23 & 1.74 \\
\hline & Bias(\%) & 8.26 & 1.25 & 3.07 \\
\hline & Sigma & 4.48 & 3.02 & 4.72 \\
\hline \multirow{3}{*}{ Şubat Level 3} & CV(\%) & 3.86 & 0.97 & 2.39 \\
\hline & Bias(\%) & 6.99 & 5.78 & 3.92 \\
\hline & Sigma & 4.32 & 2.27 & 3.08 \\
\hline \multirow{3}{*}{ Mart Level 1} & $\mathrm{CV}(\%)$ & 4.31 & 2.57 & 6.41 \\
\hline & Bias(\%) & 1.99 & 0.09 & 0.18 \\
\hline & Sigma & 5.04 & 3.07 & 1.73 \\
\hline \multirow{3}{*}{ Mart level 2} & CV(\%) & 3.56 & 1.89 & 3.78 \\
\hline & $\operatorname{Bias}(\%)$ & 4.96 & 2.43 & 0.31 \\
\hline & Sigma & 5.25 & 2.93 & 2.91 \\
\hline \multirow{3}{*}{ Mart Level 3} & $\mathrm{CV}(\%)$ & 4.28 & 1.95 & 3.22 \\
\hline & Bias(\%) & 0.41 & 1.03 & 2.09 \\
\hline & Sigma & 5.42 & 3.56 & 2.86 \\
\hline
\end{tabular}

Nar ve arkadaşlarının 18 hormon testinin üç aylık ve iki farklı seviyedeki İKK verilerinin sigmametrik değerlendirmesi ile yaptıkları çalışmada bizim çalışmamıza benzer şekilde TSH için sT3 ve sT4'e kıyasla daha yüksek sigma değerleri saptamışlardır. (8). Gülbahar ve arkadaşlarının Roche Cobas e602 otoanalizöründe TSH, ST3 ve ST4 için yaptıkları sigmametrik değerlendirmede ise TSH ve sT4 için sT3'e kıyasla daha yüksek sigma değerleri hesaplamışlardır(10). Benzer bir diğer çalışmada da Beckman Coulter UniCel $₫$ Dxl800 immunoassay cihazında TSH, sT3 ve sT4 için 1 aylık IKK verilerinin sigmametrik değerlendirmesinde performansın TSH için kabul edilebilir; ancak sT3 ve sT4 için ise kabul edilemez durumda olduğu gösterilmiştir (11). Her üç çalışma bizim çalışmamıza benzer olarak TSH'ın nispeten yüksek sT3 ve sT4'ün ise nispeten düşük sigma değerleri ortaya koyması, ST3 ve sT4 testlerinin standardizasyonunun gerekliliğini düşündürmüştür. Çalışmamızdaki sigma değerleri, diğerlerinden farklı olarak 3 farklı İKK verilerinden yararlanılarak hesaplanmıştır. Kontrol seviyeleri arasında sigma değerlerinin birbirinden çok farklı olması, hipotiroidinin klinik derinliği arttıkça TSH düzeylerinin raporlamasında daha fazla dikkat edilmesinin gerekliliğini ortaya koymuştur.

Tablo 3. Kalite kontrol stratejisi

\begin{tabular}{ccc}
\hline Sigma metrik & Kalite performansı & Westgard Kuralı \\
\hline$<3$ & Yetersiz & $1_{3 \mathrm{~S}} / 2_{2 \mathrm{~S}} / \mathrm{R}_{4 \mathrm{~S}} / 4_{1 \mathrm{~S}}$ \\
$3-4$ & Uygun ancak sıkı & $1_{3 \mathrm{~S} / 2} 2_{2 \mathrm{~S}} / \mathrm{R}_{4 \mathrm{~S}} / 4_{1 \mathrm{~S}}$ \\
& kontrol & $1_{2.5 \mathrm{~S}}$ \\
$4-6$ & Uygun & $1_{3 \mathrm{~S}}$ \\
$>6$ & Çok iyi &
\end{tabular}

Sigmametrik değerlendirme, sadece hormon ve biyokimya testlerinde değil; tüm laboratuvar pratiğinde her geçen gün daha çok geçerliliğini ve önemini ortaya koymaktadır. Çeken ve arkadaşlarının mikrobiyoloji laboratuvarı preanalitik evre sigmametrik değerlendirmesi buna örnek olarak gösterilebilir (12).

Sigmametrik değerlendirmeyi laboratuvarımızda tiroid fonksiyon testleri için uyguladığımız çalışmamızda TSH için iyi, ST3 ve sT4 testleri için ise düzeltilmesi gereken düzeyde olduğunu saptadık. Genellikle laboratuvarlar İKK verilerinden elde edilen $C V$ ve SD değerleri ile analitik dönem kalitesini yönetse de, sigmametrik değerlendirme daha sıkı bir İKK yapmamı gerektiğini bize göstermiştir. Westgard(13) tarafından önerilen kontrol kuralları (Tablo 3) bakımından;TSH, sT3 ve sT4 testlerimizin sigma değeri>4 ve üzerindeki sonuçlarda günlük takip edilen kontrol seviyesimizin $1_{2.5 s}$ kuralı, sigma değeri <3'ün altındaki testlerimizin $1_{3 S} / 2_{2 s} / R_{4 S} / 4_{1 s}$ kuralının takip edilmesi ile daha iyi bir performans sağlanacağı kanaatindeyiz. 
Sonuç olarak, bu çalışma analitik evre için sigmametrik değerlendirmede immunokimya açısından değerli bilgiler vermiştir. Bu alanda yeni yapılacak birçok çalışmaya intiyaç duymaktadır. Bu bağlamda hormon analitik evre değerlendirmesinde çalışmamızın bir katkı sağlayacağını umuyoruz.

\section{Kaynaklar}

1. Forsman RW. Why is the laboratory an afterthought for managed care organizations? Clinical chemistry. 1996;42(5):813-6.

2. Mao X, Shao J, Zhang B, Wang Y. Evaluating analytical quality in clinical biochemistry laboratory using Six Sigma. Biochemia medica. 2018;28(2):020904.

3. Nanda SK, Ray L. Quantitative application of sigma metrics in medical biochemistry. Journal of clinical and diagnostic research : JCDR. 2013;7(12):2689-91.

4. Hens K, Berth M, Armbruster D, Westgard S. Sigma metrics used to assess analytical quality of clinical chemistry assays: importance of the allowable total error (TEa) target. Clinical chemistry and laboratory medicine. 2014;52(7):973-80.

5. Plebani M, Sciacovelli L, Aita A, Padoan A, Chiozza ML. Quality indicators to detect pre-analytical errors in laboratory testing. Clinica chimica acta; international journal of clinical chemistry. 2014;432:44-8.

6. Nevalainen D, Berte L, Kraft C, Leigh E, Picaso L, Morgan T. Evaluating laboratory performance on quality indicators with the six sigma scale. Archives of pathology \& laboratory medicine. 2000;124(4):516-9. 7. Ricós C, Alvarez V, Cava F, Garcia-Lario J, Hernandez A, Jimenez $\mathrm{C}$, et al. Current databases on biological variation: pros, cons and progress. Scandinavian journal of clinical and laboratory investigation. 1999;59(7):491-500.

8. Nar R, Emekli DI. The evaluation of analytical performance of immunoassay tests by using six-sigma method. Journal of medical biochemistry. 2017;36(4):301-8.

9. Bekkering GE, Agoritsas T, Lytvyn L, Heen AF, Feller M, Moutzouri $E$, et al. Thyroid hormones treatment for subclinical hypothyroidism: a clinical practice guideline. BMJ (Clinical research ed). 2019;365:I2006. 10. Gulbahar O, Arslan B, Sen B, Cingirt M, YIImaz SN. Evaluation of thyroid function tests in our laboratory by using six sigma analysis. Turkish Journal of Biochemistry, 2015; 40 (S1)

11. Ercan M, Bogdaycioglu N, Akbulut ED, Oguz E, Topcuoglu C et al. Assessment of the analytic performance for immunassay tests with six sigma methodology. Clin Chem Lab Med 2015; 53, Special Suppl, pp S1-S1450.

12. Ceken N, Avcı E, Duran H, Tibbi Mikrobiyoloji Laboratuvarında Preanalitik Hataların Sigmametrik Değerlendirilmesi, Türk Mikrobiyol Cem Derg 2018;48(2):141-146

13. Westgard J, Westgard S. An Assessment of $\sigma$ Metrics for Analytic Quality Using Performance Data From Proficiency Testing Surveys and the CLIA Criteria for Acceptable Performance. Am J Clin Pathol 2006;125(3):343-54 